\title{
Managing the menopause
}

\author{
Helen Roberts
}

Department of Obstetrics and

Gynaecology, University of

Auckland, Private Bag 92019,

Auckland, New Zealand

h.roberts@auckland.ac.nz

BMJ 2007;334:736-41

doi: 10.1136/bmj.39153.522535.BE
The transition into the menopause usually begins with elongation of cycle length, the term postmenopausal being used after one year with no periods. ${ }^{1}$ Most women experience menopause between 40 and 58 years of age. ${ }^{1}$ No menopausal symptom is universal. ${ }^{\mathrm{w} 1}$ In Western society the commonest symptoms are hot flushes, night sweats, vaginal dryness, and sleep disturbance. ${ }^{2}$ Many women manage the menopause by themselves, with only about $10 \%$ seeking help from healthcare providers. ${ }^{2}$ Hormone replacement therapy is the most effective treatment for symptoms $(\text { table } 1)^{3}$ and although opinions are still polarised advice on its use has changed after the women's health initiative studies. ${ }^{4}$

\section{What are the indications for hormone replacement therapy?}

Menopausal symptoms

Indications for hormone replacement therapy are hot flushes, night sweats, and vaginal dryness (table 1). ${ }^{3} \mathrm{~A}$ Cochrane review of randomised trials showed a 75\% reduction in flushes (18 fewer per week) with therapy compared with a $50 \%$ reduction with placebo. ${ }^{5}$

Flushes can start while a woman is still having periods. Her perception of severity of symptoms will be the deciding factor for offering treatment, not hormone levels, as they fluctuate throughout the perimenopause. Improvements can occur within four weeks of starting therapy. ${ }^{\mathrm{w} 2}$

Advice from most, ${ }^{36 \text { w3 w4 }}$ although not all, sources ${ }^{7}$ is to use the lowest dose of hormone for the shortest duration to give symptom relief. Short term use is also clinically appropriate as flushes disappear within a few years of menopause for about two thirds of women. ${ }^{6}$

Evidence from longitudinal studies does not suggest that mood symptoms are increased at menopause and at present information is insufficient to conclude any causal relation between the transition into menopause and cognitive disturbances. ${ }^{16}$ Disturbances in cognition and mood are not indications for hormone replacement therapy.

Urogenital symptoms are more common after the menopause and occur in up to $50 \%$ of women. ${ }^{6}$ Hormone replacement therapy makes incontinence worse, but vaginal oestrogen preparations benefit dyspareunia and decrease recurrent urinary tract infections in susceptible women (table 1). ${ }^{3}$ Response can take one or two months and as these symptoms are not usually self limiting long term use is needed. Systemic absorption is minimal so that the risks from oral oestrogen do not apply and women with a uterus do not need to use progestogen. ${ }^{6}$

\section{Prevention of chronic disease}

Long term hormone replacement therapy for the prevention of chronic disease is no longer recommended as negative outcomes outweigh positive benefits, as shown in both the oestrogen only and combined arms of the women's health initiative studies. ${ }^{8}$ The participants in the studies were women aged 50-79 using $0.625 \mathrm{mg}$ conjugated equine oestrogen alone or with $2.5 \mathrm{mg}$ medroxyprogesterone acetate. Results showed a statistically significant increase in stroke, deep vein thrombosis, and gallbladder disease for both the combined and oestrogen only treatments, with additional increases in breast cancer and dementia (women aged $>65$ ) for combined therapy (table 2) ${ }^{9-19}$ Statistically significant benefits were shown for fracture with both treatments and for colorectal cancer with combined therapy. The differences in absolute risk are listed on bmj.com. ${ }^{910}$ The risks are likely to be lower for healthy perimenopausal women using lower doses of hormone. These small increases in absolute risk for a few years are usually acceptable to women with troublesome symptoms.

Women with premature menopause usually have severe flushes requiring treatment and may often need higher doses of hormone. ${ }^{1}$ Evidence of other additional benefits is not substantial. ${ }^{6}$

\section{What should women do about bone?}

As bone density decreases with age, advice should be given on the benefits of adequate calcium, vitamin $\mathrm{D},{ }^{\mathrm{w} 5}$ and weight bearing exercise. Bone density screening for all menopausal women is not recommended;

\section{Sources and selection criteria}

This review is based on a search of Medline, the Cochrane Database of Systematic Reviews, and citation lists of relevant publications. The subject headings and key words used were "menopause", "hormone replacement therapy", "WHI", "hot flushes", "vaginal dryness", "tibolone", "testosterone", and "complementary". 
however, guidelines do support the assessment of osteoporosis risk at menopause and measurement of bone mineral density using dual energy $\mathrm{x}$ ray absorptiometry for those at risk. These are women aged more than 40 with fragility fractures, those using systemic glucocorticoids for more than three months, those aged less than 65 with risk factors (for example, family history of osteoporotic fracture), and those aged more than $65 .{ }^{20}$ If follow-up measurement of bone mineral density is necessary readings should be taken on the same machine to reduce precision error. Treatment should be considered for those with $\mathrm{T}$ scores below -2.5 , or below -1.5 if one major clinical risk factor is present. $^{20 \mathrm{w} 6}$

As with previous studies, the women's health initiative studies showed a decreased risk of fracture with hormone replacement therapy. ${ }^{910}$ Most studies have shown that long term use is required for protection. Although agreement is not general, ${ }^{\mathrm{w} 7}$ most sources do not recommend long term treatment for osteoporosis because of the unfavourable riskbenefit ratio. ${ }^{321}$

In the women's health initiative studies, risks still outweighed the benefit for fracture even for those women at highest risk of fracture. ${ }^{\text {w8 }}$ Bisphosphonates are recommended as first line treatment and with these the benefit for fracture has only been shown for women with osteoporosis (T score $\leq 2.5){ }^{6}$

\section{What needs to be done before starting therapy?}

A full personal and family history will highlight women with risk factors. Risk assessment for cardiovascular disease should include measurement of body mass index, blood pressure, and lipid levels. Women with previous breast cancer, coronary heart disease, stroke, dementia, or venous thromboembolism should not use hormone replacement therapy as randomised studies have shown an increased risk of further disease. ${ }^{622}$ Individualised risk can be assessed for women with risk factors for cardiovascular disease - that is, trial evidence can be translated to individual decisions by transforming relative risk into absolute risks. For example, hormone replacement increases the risk of stroke by $40 \%$ (relative risk 1.4 ). A woman with a $5 \%$ baseline risk then has a $7 \%(5 \times 1.4)$ risk with hormone replacement therapy, which is only a $2 \%$ increase. If she has a $25 \%$ baseline risk, however, the risk with hormone replacement therapy is $35 \%$ $(25 \times 1.4)$, a $10 \%$ increase. $^{23}$

\section{How is hormone replacement given?}

Oestrogen is available as oral tablets, transdermal patches or gels, nasal sprays, and implants, although availability differs across countries. Few clinical data are available to advise women about any different safety profile with hormones other than those used in the women's health initiative studies (conjugated equine oestrogens alone or with medroxyprogesterone acetate).

At present most women start with oral therapy at a low dose (0.3 mg conjugated equine oestrogen, 0.5-1.0 $\mathrm{mg}$ of $17-\beta$-estradiol or estradiol valerate) as this has been shown to relieve flushes. ${ }^{\mathrm{w} 9}$ The dose can be increased if relief of symptoms is not adequate after a few weeks. Women who have had a hysterectomy can use unopposed oestrogen; the addition of progestogen is required for women with a uterus to reduce endometrial hyperplasia, which is increased even with low doses of oestrogen. ${ }^{\mathrm{w} 9}$ Combined continuous regimens (oestrogen and progestogen daily) can be used when the woman has been postmenopausal for more than one year; before this, sequential regimens (oestrogen daily with progestogen 10-14 days each month) are

Table 1 | Grades of evidence for symptom relief at menopause ${ }^{3}$

\begin{tabular}{|c|c|c|}
\hline Symptoms and treatment & Effectiveness of treatment & Level of evidence* \\
\hline \multicolumn{3}{|l|}{ Hot flushes, night sweats: } \\
\hline Hormone replacement therapy & $\begin{array}{l}\text { Both unopposed oestrogen and oestrogen } \\
\text { progestogen therapy are effective treatment for hot } \\
\text { flushes }\end{array}$ & A \\
\hline Tibolone & $\begin{array}{l}\text { Effective for alleviating severity and reducing } \\
\text { frequency of hot flushes }\end{array}$ & A \\
\hline \multicolumn{3}{|l|}{ Vaginal atrophy, recurrent urinary tract infections: } \\
\hline Low dose topical oestrogen & $\begin{array}{l}\text { Cream or tablet form or as estradiol releasing ring is } \\
\text { an effective treatment for symptoms of vaginal } \\
\text { atrophy }\end{array}$ & A \\
\hline Intravaginal oestrogen therapy & $\begin{array}{l}\text { Treatment for 6-8 months results in reduced } \\
\text { recurrence of urinary tract infections in susceptible } \\
\text { women }\end{array}$ & B \\
\hline Tibolone & Has been shown to be effective for vaginal atrophy & B \\
\hline Vaginal moisturiser Replens (Meda, Solna, Sweden) & $\begin{array}{l}\text { Effective non-hormonal treatment that may offer } \\
\text { relief from vaginal dryness }\end{array}$ & B \\
\hline
\end{tabular}

*Grading system from Scottish Intercollegiate Guidelines Network. A=well designed meta-analysis of randomised controlled trials, or body of evidence that is consistently applicable; B=very well designed observational studies or extrapolated evidence from randomised controlled trials or meta-analyses. 
appropriate. Combined continuous regimens in early menopause may cause irregular bleeding, as oestrogen production from the ovaries is often still fluctuating. Use of prepacked products simplifies use; however, these may notyet be available in low dose format for all combined regimens and may mean that the hormones have to be prescribed individually.An easy rule of thumb to ensure adequate progestogen for protection of the endometrium is to extrapolate doses from those in prepackaged regimens. Low doses of progestogens such as norethisterone and levonorgestrel can be obtained from progestogen only pills.

For those women still menstruating, oestrogen should be started on the first day of the menstrual bleed and progestogen given 14 days later. Withdrawal bleeding should then start around the same time that the period would be expected.

Common side effects of hormone replacement therapy reported from randomised studies include irregular bleeding with combined regimens, which usually settles after a few months, and nausea and breast tenderness. These usually decrease over time, but in clinical practice lowering the dose of hormones reduces these side effects. ${ }^{5}$

Oestrogen can also be given by transdermal patch. Although transdermal oestrogen has little effect on haemostasis, further evidence is required before we can give advice on a lower thrombotic risk compared with oral oestrogen.

Oestrogen given by implant is usually best reserved for specialised centres. Women who have had an early surgical menopause and whose symptom relief with other means of administration is not adequate may find implants useful. Symptoms may return, however, despite super physiological levels of oestradiol (tachyphylaxis). Implants are not normally recommended for women who have a uterus, as prolonged stimulation of the endometrium may occur, requiring continuation of progestogen even after the implants are stopped. ${ }^{\mathrm{w} 10}$

Progestogen is available as an oral tablet, transdermal patch, or intrauterine system. The intrauterinesystem gives good protection of the endometrium and, unlike other combined hormone replacement therapies, offers both contraception and less bleeding for perimenopausal women. ${ }^{\text {w11 w12 }}$

\section{What are the bleeding patterns with hormone replacement therapy and how should irregular patterns be investigated?}

Most women using the sequential regimen have a withdrawal bleed near the end of the progestogen dose. This is usually lighter than a period. Combined continuous regimens can give irregular spotting in the first 6-12 months of use, but at the end of the first year most women do not bleed. Endometrial investigation (ultrasonography to determine the thickness of the endometrium or pipelle biopsy) is not required before starting hormone replacement therapy unless there has been bleeding between periods or bleeding after one year with no periods.

If irregular bleeding persists during treatment compliance should be checked and cervical malignancy or infection ruled out before referring for investigation.

\section{What advice can be given about stopping therapy?}

Observational data show that for women starting hormone replacement therapy 40-50\% stop within one year and $65-75 \%$ stop within two years, usually without needing to visit a healthcare provider. ${ }^{24}$ Good evidence is lacking on the best way to stop treatment. The initial approach could be to ask women to stop within one or two years of starting therapy to see if symptoms have gone. Women with severe return of flushes could then be advised to restart therapy but to slowly decrease the dose over the next 3-6 months. Addition of other nonhormonal treatments that help flushes has been suggested to help women who have symptoms during withdrawal, particularly those who are at high risk of adverse events while using therapy. ${ }^{624}$ Women with long term debilitating symptoms will need to balance symptom relief with ongoing risks from therapy.

\section{Are there other treatments that can help menopausal symptoms?}

The Royal College of Obstetricians and Gynaecologists advises that regular aerobic exercise such as swimming and running may help with flushes, as can reduction of caffeine and alcohol intake. ${ }^{25}$ Limited

\begin{tabular}{|c|c|c|}
\hline Outcome & $\begin{array}{l}\text { Hazard ratio }(95 \% \mathrm{Cl}) \text { for combined } \\
\text { oestrogen progestogen }\end{array}$ & Hazard ratio $(95 \% \mathrm{Cl})$ for oestrogen only \\
\hline Stroke (mainly ischaemic) & $1.41(1.07 \text { to } 1.85)^{9}$ & $1.39(1.10 \text { to } 1.77)^{10}$ \\
\hline Breast cancer (final results) & $1.24(1.01 \text { to } 1.54)^{11}$ & $0.77(0.59 \text { to } 1.01)^{12}$ \\
\hline Deep vein thrombosis & $1.95(1.43 \text { to } 2.67)^{13}$ & $1.47(1.06 \text { to } 2.06)^{14}$ \\
\hline Coronary heart disease (final results) & $1.24(1.00 \text { to } 1.54)^{15}$ & $0.77(0.59 \text { to } 1.01)^{16}$ \\
\hline Dementia (women $>65$ years) & $2.05(1.21 \text { to } 3.48)^{17}$ & $1.49(0.83 \text { to } 2.66)^{18}$ \\
\hline Gall bladder disease and procedure & $1.59(1.20 \text { to } 1.97)^{19}$ & $1.67(1.35 \text { to } 2.06)^{19}$ \\
\hline Hip fracture & $0.66(0.45 \text { to } 0.98)^{9}$ & $0.61(0.41 \text { to } 0.91)^{10}$ \\
\hline Total fracture & $0.76(0.69 \text { to } 0.85)^{9}$ & $0.70(0.63 \text { to } 0.79)^{10}$ \\
\hline Colorectal cancer & $0.63(0.43 \text { to } 0.92)^{9}$ & $1.08(0.75 \text { to } 1.55)^{10}$ \\
\hline Total mortality & $0.98(0.82 \text { to } 1.18)^{9}$ & $1.04(0.88 \text { to } 1.22)^{10}$ \\
\hline
\end{tabular}




\section{SUMMARY POINTS}

Hormone replacement therapy remains an appropriate treatment for women with moderate to severe menopausal symptoms

Hormone replacement therapy should not be used for the prevention of chronic disease

Treatment should be at the lowest dose for the shortest time necessary to control symptoms

Women should be advised of the increased risk of stroke, deep vein thrombosis, and gallbladder disease with both combined and oestrogen only therapy

Combined therapy is also associated with increases in risk of breast cancer and dementia (women aged >65) we have no data to advise women that risks are different from conventional hormone replacement therapy. Progestogen should be added to protect the endometrium in women with a uterus. Testing for hormones in saliva is often suggested with use of bioidentical hormones but is not thought to be useful. ${ }^{27}$ The treatments discussed for women with previous breast cancer are also the choices for other menopausal women with flushes.

\section{What are the treatments for women with previous breast cancer?}

evidence also exists for acupuncture and for paced respirations. ${ }^{6}$

Tibolone, a synthetic steroid with weak oestrogenic, progestogenic, and androgenic properties, has shown benefit for flushes and vaginal dryness (table 1). At present data are lacking from randomised studies to enable advice on outcomes such as breast cancer and cardiovascular disease. ${ }^{26}$

Randomised studies have shown that progestogens can benefit flushes (for example, Depo-Provera (Pharmacia) $150 \mathrm{mg}(90 \%$ v 25\% fewer flushes compared with placebo) or oral medroxyprogesterone acetate $20 \mathrm{mg}$ daily $(74 \%$ v 26\% fewer flushes compared with placebo). ${ }^{27}$ These doses can be used in women with previous venous thromboembolism.

Progesterone cream (20 mg and $32 \mathrm{mg}$ daily) has been evaluated in two randomised studies, one showing benefit (20 mg daily) for flushes (83\% women improved $v$ 19\% placebo), the other not. ${ }^{\text {w13 }}$ Data are insufficient to give assurance that progesterone cream will provide adequate protection of the endometrium for women using oestrogen.

Since the publication of the women's health initiative studies the use of bioidentical hormones for flushes has increased, usually in the form of transdermal creams or troches (similar to lozenges or pastilles). These are often a mixture of low doses of estradiol $(0.5 \mathrm{mg})$ along with estriol (Biest cream) or also including estrone (Triest cream).These products are compounded in pharmacies and are not available commercially. Clinical efficacy for relief of flushes is likely to result from the estradiol component, ${ }^{\mathrm{w} 2}$ w9 and
Flushes are often severe for women with a history of breast cancer, either from the effects of chemotherapy and ovarian ablation or from the side effects of adjuvant therapy such as tamoxifen and aromatase inhibitors. ${ }^{28}$ One randomised study of hormone use in women with previous breast cancer showed an increase in recurrence compared with placebo. ${ }^{29}$ Any hormonal therapy, including progestogen alone, is considered to be contraindicated for women with pre-

Clonidine has shown some benefit for flushes compared with placebo. Transdermal clonidine $0.1 \mathrm{mg} /$ day seems to be more useful than oral clonidine $(0.1 \mathrm{mg}$ and $0.2 \mathrm{mg})$. Side effects include dry mouth, constipation, drowsiness, and dizziness, but no effect on blood pressure at these doses. Clonidine can, however, enhance the effects of other antihypertensives, anxiolitics, and alcohol. ${ }^{28}$

Both selective serotonin reuptake inhibitors and selective noradrenaline reuptake inhibitors have been shown to reduce flushes $(60 \%)$ compared with placebo $(30 \%)$, perhaps due to the role of serotonin in the pathophysiology of flushes. The benefit of these products over placebo can also be presented by the daily improvement in the number of flushes (see bmj.com). ${ }^{30}$ Most of the randomised studies have been of short duration (4-12 weeks). Venlaflaxine (37.5 mg and $75 \mathrm{mg})$, fluoxetine $(20 \mathrm{mg})$, and paroxetine $(12.5 \mathrm{mg}$ and $25 \mathrm{mg}$ ) have all shown benefit. Advice is to start at the lower doses and titrate upwards and also to taper the dose at withdrawal. Although these drugs are generally well tolerated, possible side effects include dry vious breast cancer.

\section{ADDITIONAL EDUCATIONAL RESOURCES}

National Institutes of Health (http://consensus.nih.gov/)

Statement from a state of science conference on management of menopause related symptoms, 2005

Royal College of Obstetricians and Gynaecologists (www.rcog.org.uk/index.asp?PagelD=310)

A statement from the Menopause and Hormone Replacement Study Group

Royal College of Obstetricians and Gynaecologists. Scientific Advisory Committee. Opinion paper 6 May 2006 (www.rcog. org.uk/index.asp?PagelD=1561)

Alternatives to hormone replacement therapy for the management of menopausal symptoms

Useful websites

Women's health initiative study (www.nhlbi.nih.gov/whi/)

This website contains a videocaste, information kit, and details of publications from the women's health initiative study

New Zealand Guidelines Group (www.nzgg.org.nz/guidelines/dsp_guideline_popup.cfm?guidelinelD=78)

Pamphlet on oestrogen plus progestogen for consumers 
mouth, dizziness, nausea, and constipation. They also have the potential to decrease libido. At present there is discussion on the possible effects of selective serotonin reuptake inhibitors on the efficacy of tamoxifen. Tamoxifen is converted to its active metabolites by cytochrome $P-450$, and paroxetine, fluoxetine, and possible other selective serotonin reuptake inhibitors have potential to inhibit this conversion. Venlaflaxine would seem to be a weaker inhibitor. ${ }^{28}$

The anti-epileptic gabapentin (900 mg/day) has also been shown to provide benefit for flushes in women with breast cancer. ${ }^{30}$ The side effect profile may, however, restrict the use to specialised centres. ${ }^{25}$

Most of the studies of the herbal remedy black cohosh are of short duration and have had mixed results. A recent randomised trial in women with breast cancer who were taking tamoxifen did, however, find benefit for flushes over placebo. ${ }^{6}$ The commercially available product Remifemin (GlaxoSmithKline, Pittsburgh, PA) has been the most widely studied. Although one case of acute hepatitis has been reported, overall the product seems safe for short term use.

Meta-analysis showed a small reduction in flushes from red clover isoflavones $40-82 \mathrm{mg} / \mathrm{day} .{ }^{25}$ At present black cohosh and red clover are not thought to have any effects on breast or endometrium, although long term data are needed.

Other studies on phyto-oestrogens have shown mixed results, but the four trials in women with previous breast cancer found no difference in flushes with soy isoflavones compared with placebo. ${ }^{30}$ The effects on the breast of long term treatment with these products is not clear but they have been shown to cause endometrial hyperplasia. ${ }^{6}$

Vitamin E has shown a small benefit over placebo, with one less hot flush daily. ${ }^{25}$ Dehyroepiandrosterone, soy products, dong quai, evening primrose oil, or ginseng do not seem to benefit flushes. ${ }^{25}$ Replens (Meda, Solna, Sweden), a vaginal moisturiser, can be used for vaginal symptoms (table 1). ${ }^{\text {w14 }}$

\section{ADDITIONAL EDUCATIONAL RESOURCES}

\section{Other cochrane reviews of menopausal and older women}

Hogervorst E, Yaffe K, Richards M, Huppert F. Hormone replacement therapy for cognitive function in postmenopausal women. Cochrane Database Syst Rev 2002;(2):CD003122

Found little evidence on the effect of hormone replacement therapy or oestrogen replacement therapy on overall cognitive function in healthy postmenopausal women, although some small studies showed some benefit of bolus intramuscular injections of estradiol for younger surgically menopausal women

Hogervorst E, Yaffe K, Richards M, Huppert F. Hormone replacement therapy to maintain cognitive function in women with dementia. Cochrane Database Syst Rev 2002;(3):CD003799

Concluded that neither hormone replacement therapy nor oestrogen replacement therapy was indicated for cognitive improvement or maintenance in women with Alzheimer's disease

Evans GJ, Malouf R, Huppert F, van Niekerk JK. Dehydroepiandrosterone (DHEA) supplementation for cognitve function in healthy elderly people. Cochrane Database Syst Rev 2006;(4):CD006221

Did not support a beneficial effect of dehydroepiandrosterone supplementation on cognitive function of non-demented middle aged or elderly people

Birks J, Grimley EV, Van Dongen M. Ginkgo biloba for cognitive impairment and dementia. Cochrane Database Syst Rev 2002;(4):CD003120

Promising although inconsistent evidence of improvement in cognition with Ginkgo. Side effects similar to placebo

Suckling J, Lethaby A, Kennedy R. Local oestrogen for vaginal atrophy in postmenopausal women. Cochrane Database Syst Rev 2006;(4):CD001500

All vaginal delivery systems (cream, tablets, pessary, ring) were equally effective for the symptoms of vaginal atrophy, although conjugated equine oestrogen cream caused overstimulation of the endometrium

Kongnyuy EJ, Norman RJ, Flight IHK, Rees MCP. Oestrogen and progestogen therapy for perimenopausal and postmenopausal women: weight and body fat distribution. Cochrane Database Syst Rev 1999;(3):CD001018 No effect of oestrogen alone or with progestogen on the body mass index increase normally experienced at the time of menopause

Lethaby A, Suckling J, Barlow D Farquhar CM et al. Hormone replacement therapy in postmenopausal women: endometrial hyperplasia and irregular bleeding. Cochrane Database Syst Rev 2004;(3):CD000402

Unopposed oestrogen therapy in women with a uterus was associated with increased rates of endometrial hyperplasia, irregular bleeding, and consequent non-adherence to therapy. The addition of oral progestogens given sequentially or continuously was associated with reduced rates of hyperplasia and there was a suggestion that continuous therapy over long duration is more protective than sequential therapy in the prevention of endometrial hyperplasia. Hyperplasia was more likely when progestogen was given every three months in a sequential regimen compared with every month in a sequential regimen

Gabriel-Sanchez R,Carmona L, Rogue M, et al. Hormone replacement therapy for preventing cardiovascular disease in post-menopausal women. Cochrane Database Syst Rev 2005;(2):CD002229.

This review of combined hormone replacement therapy found no protective effect for any cardiovascular outcome, and increased risk of venous thromboembolic events(relative risk 2.15), pulmonary embolus (2.15), and stroke (1.44) compared with placebo 


\section{Testosterone replacement}

The American Endocrine Society does not recommend the generalised use of testosterone in women. ${ }^{31}$ It points out that no data exist to advise women on risks from long term use. The main evidence of benefit for testosterone is for women with surgical menopause, when it was used along with hormone replacement. Improvement was found in sexual function compared with hormone replacement alone. ${ }^{\text {w15 }}$ This meta-analysis had various modalities of replacement including testosterone implants and transdermal patches. The study lasted a median of six months, with the main adverse effect being a decrease in high density lipoprotein cholesterol levels. ${ }^{\text {w15 }}$ Evidence of a treatment effect for perimenopausal women was insufficient. As testosterone is not approved for use in women in most countries, referral to specialised centres is advised.

\section{What does the future hold?}

Despite hormone replacement therapy being available for 60 years there are still many gaps in our knowledge. Ongoing longitudinal data on menopausal symptoms are needed for other ethnic groups. More research is needed on alternative therapies to tackle standardisation of dose, along with clinical efficacy. Larger randomised controlled trials for selective serotonin reuptake inhibitors and selective noradrenaline reuptake inhibitors are required to look at efficacy and the degree of interaction with tamoxifen.

It would be useful to have more information to advise women in the 50-59 years age group, who are the most likely users of hormone therapy for symptom relief. In the past few years subgroup analysis of results from the women's health initiative studies has been ongoing in this age group. The number of events is small, however, and the studies were not powered to examine them. Thus many of the reported interactions for these younger women may be spurious and due to chance alone. ${ }^{23}$ In this age group the only significant outcome (when the confidence interval did not include 1) was the increase in risk of deep vein thrombosis with combined replacement therapy (see bmj.com). ${ }^{32}$ These subgroup analyses are, however, useful to generate hypotheses for much needed further study in these younger postmenopausal women. Some studies, such as the Kronos early estrogen prevention study, ${ }^{\text {w16 }}$ are under way.

Competing interests: None declared.

This article was commissioned by the $B M J$ and has been peer reviewed.

1 National Institutes of Health state of science conference statement on management of menopause-related symptoms. NIH, 2005. http://consensus.nih.gov/

2 Woods NF, Mitchell ES. Symptoms during the perimenopause: prevalence, severity, trajectory, and significance in women's lives. Am J Med 2005;118:S14-24.

3 New Zealand Guidelines Group. Hormone replacement therapy. Summary document 2004. www.nzgg.org.nz/guidelines/0078/ HRT_summary_web.pdf

4 Roberts HE, Farquhar CM. Advice has changed for hormone therapy in the WHI era. Aust N Z J Obstet Gynaecol 2006;46:74-6.

5 MacLennan AH, Lester S, Moore V. Oral estrogen replacement therapy versus placebo for hot flushes. Cochrane Database Syst Rev 2002;1:CD002978.

6 Hickey M, Davis SR, Sturdee DW. Treatment of menopausal symptoms: what shall we do now? Lancet 2005;366:409-21.
7 Guidelines for hormone treatment of women in the menopausal transition and beyond. Position statement by the Executive Committee of the International Menopause Society. Maturitas 2005;51:15-20.

8 Farquhar CM, Marjoribanks J, Lethaby A, Lamberts Q, Suckling JA, Cochrane HT Study Group. Long term hormone therapy for perimenopausal and postmenopausal women. Cochrane Database Syst Rev 2005;(3):CD004143.

9 Writing Group for the Women's Health Initiative. Risks and benefits of estrogen plus progestin in healthy postmenopausal women. JAMA 2002;288:321-33.

10 Women's Health Initiative Steering Committee. Effects of conjugated equine estrogen in postmenopausal women with hysterectomy. JAMA 2004;291:1701-12.

11 Chlebowski RT, Hendrix S, Langer RD, Stefanick ML, Gass M, Lane D, et al. Influence of estrogen plus progestin on breast cancer and mammography in healthy postmenopausal women. JAMA 2003;289:3243-53.

12 Stefanick ML, Anderson GL, Margolis KL, Hendrix SL, Rodabough RJ, Paskett ED, et al. Effects of conjugated equine estrogens on breast cancer and mammography screening in postmenopausal women with hysterectomy. JAMA 2006;295:1647-57.

13 Cushman M, Kuller LH, Prentice R, Rodabough RJ, Psaty BM, Stafford RS, et al. Estrogen plus progestin and risk of venous thrombosis. JAMA 2004;292:1573-80.

14 Curb JD, Prentice RL, Bray PF, Langer RD, van Horn L, Barnabei VM, et al. Venous thrombosis and conjugated equine estrogen in women without a uterus. Arch Intern Med 2006;166:772-80.

15 Manson JE, Hsia J, Johnson KC. Estrogen plus progestin and the risk of coronary heart disease. N Engl J Med 2003;349:523-34.

16 Hsia J, Langer RD, Manson JE, Kuller L, Johnson KC, Hendrix SL, et al. Conjugated equine estrogens and coronary heart disease. Arch Intern Med 2006;166:357-65.

17 Shumaker SA, Legault C, Rapp SR, Thal L, Wallace RB, Ockene JK, et al. Estrogen plus progestin and the incidence of dementia and mild cognitive impairment in postmenopausal women: Women's Health Initiative Memory Study. JAMA 2003;289:2651-62.

18 Shumaker SA, Legault C, Kuller L, Rapp SR, Thal L, Lane DS, et al. Conjugated equine estrogens and the incidence of probable dementia and mild cognitive impairment in postmenopausal women: Women's Health Initiative Memory Study. JAMA 2004;291:2947-58.

19 Cirillo DJ, Wallace RB, Rodabough RJ, Greenland P, LaCroix AZ, Limacher MC, et al. Effect of estrogen on gallbladder disease. JAMA 2005;293:330-9.

20 Canadian consensus conference on osteoporosis 2006 update. $J$ Obstet Gynaecol Can 2006;172:S95-112.

21 North American Menopause Society. Management of osteoporosis in postmenopausal women: 2006 position statement of the North American Menopause Society. Menopause 2006;13:348.

22 Skouby S, Al-Azzawi F, Barlow D, Calaf-Alsina Erdogan Ertungealp J, Gompel A, Graziottin A, et al. Climacteric medicine: European Menopause and Andropause Society (EMAS) 2004/5 position statements on peri-and postmenopausal hormone replacement therapy. Maturitas 2005;51:8-14.

23 Col NF. The impact of risk status, preexisting morbidity, and polypharmacy on treatment decisions concerning menopausal symptoms. (Consensus Development Conference, NIH.) Am J Med 2005;118:S155-62.

24 Grady D, Sawaya GF. Discontinuation of postmenopausal hormone therapy. Am J Med 2005;118:S163-5.

25 Royal College of Obstetricians and Gynaecologists. Scientific Advisory Committee. Alternatives to HRT for the management of symptoms of the menopause. Opinion paper 6 May, 2006. www. rcog.org.uk/index.asp?PagelD=1561

26 Kenemans $P$, Speroff L. Tibilone: clinical recommendations and practical guidelines. A report of the International Tibolone Consensus Group. Maturitas 2005;51:21-8.

27 Boothby LA, Doering PL, Kipersztok S. Bioidentical hormone therapy: a review. Menopause 2004;11:356-67.

28 Mom CH, Buijs C, Willemse PH, Mouritas MJ, de Vries EG. Hot flushes in breast cancer patients. Crit Rev Oncol Hematol 2006; 57:63-77.

29 Holmberg L, Anderson H. HABITS (hormonal replacement therapy after breast cancer-is it safe?), a randomized comparison trial stopped. Lancet 2004;363:453-5.

30 Nelson HD, Vesco KK, Haney E, Fu R, Nedrow A, Miller J, et al. Nonhormonal therapies for menopausal hot flashes. Systematic review and meta-analysis. JAMA 2006;295:2057-71.

31 Wierman ME, Bussan R, Davis SR, Khosla S, Miller KK, Rosner W, et al. Androgen therapy in women: an endocrine society clinical practice guideline. J Clin Endocrinol Metab 2006;91:3697-710.

32 LaCroix AZ. Estrogen with and without progestin: benefits and risks of short-term use. Am J Med 2005;118:S79-87. 